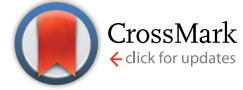

Cite this: J. Mater. Chem. A, 2017, 5, 3284

Received 20th November 2016 Accepted 13th January 2017

DOI: $10.1039 / c 6 t a 10016 c$

www.rsc.org/MaterialsA

\section{Zinc-modulated Fe-Co Prussian blue analogues with well-controlled morphologies for the efficient sorption of cesium $\uparrow$}

\author{
Jiayi Liu, ${ }^{\text {ab }}$ Xuning Li, ${ }^{\text {ab }}$ Alexandre I. Rykov, ${ }^{a}$ Qiaohui Fan, ${ }^{\text {*c }}$ Wei Xu, ${ }^{d}$ Weimin Cong, \\ Changzi Jin, ${ }^{a}$ Hailian Tang, ${ }^{\text {ab }}$ Kaixin Zhu, ${ }^{\text {ab }}$ Ayyakannu Sundaram Ganeshraja, ${ }^{a}$ \\ Rile Ge, ${ }^{a}$ Xiaodong Wang ${ }^{\mathrm{e}}$ and Junhu Wang ${ }^{\star a}$
}

Prussian blue analogues (PBAs) with tunable compositions and morphologies have demonstrated great potential in many applications. We successfully synthesized a series of $\mathrm{KFe}_{x} \mathrm{Zn}_{1-x}\left[\mathrm{Co}(\mathrm{CN})_{6}\right]\left(\mathrm{Fe}_{x} \mathrm{Zn}_{1-x}-\mathrm{Co}\right)$ PBAs with well-controlled compositions and morphologies and used them as adsorbents for the removal of $\mathrm{Cs}^{+}$ions. The increase of $\mathrm{Zn}$ : Fe ratio had a significant influence on the final morphology and improved the sorption capacity for Cs. X-ray diffraction and X-ray absorption fine structure spectra were used to confirm that the $\mathrm{Cs}^{+}$ions were inserted into the crystal channels rather than simply adsorbed on the surface of the PBAs. Based on the quantitative correlation between the concentration of ions released from the PBAs and the $\mathrm{Cs}^{+}$ions adsorbed, the mechanism of $\mathrm{Cs}^{+}$sorption in the $\mathrm{Fe}_{x} \mathrm{Zn}_{1-x}-\mathrm{Co}$ PBAs was studied and a $\mathrm{Zn}^{2+}$-modulated $\mathrm{Cs}^{+}$sorption model, which illustrated the difference in sorption behavior between the $\mathrm{Fe}_{x} \mathrm{Zn}_{1-x}-\mathrm{Co}$ PBAs, was proposed and confirmed by FTIR spectra, extended X-ray absorption fine structure spectra and ${ }^{57} \mathrm{Fe}$ Mössbauer spectra. The results indicated that the $\mathrm{Fe}_{x} \mathrm{Zn}_{1-x}-\mathrm{Co}$ PBAs are excellent candidates for the removal of radioactive ${ }^{137} \mathrm{Cs}$ from nuclear waste.

\section{Introduction}

Nuclear power produces low levels of carbon emissions and is a clean and semi-renewable alternative to traditional energy sources derived from fossil fuels. ${ }^{1-3}$ However, ${ }^{137} \mathrm{Cs}$, a radioactive byproduct generated from the nuclear process, is considered to be a serious threat as a result of its relatively long halflife (30 years) and high activity. ${ }^{4-8}{ }^{137}$ Cs commonly exists and migrates as the $\mathrm{Cs}^{+}$ion in aquatic environments. Various materials, including zeolites, ${ }^{9}$ clays, ${ }^{7}$ synthetic zirconium phosphate $^{\mathbf{1 0}}$ and layered sulfide frameworks, ${ }^{11}$ have been developed as sorbents for the removal of $\mathrm{Cs}^{+}$ions from solution. However, most of these methods are expensive and have complicated synthetic processes or low sorption capacities.

${ }^{a}$ Mössbauer Effect Data Center, Dalian Institute of Chemical Physics, Chinese Academy of Sciences, Dalian 116023, China. E-mail: wangjh@dicp.ac.cn

${ }^{b}$ University of Chinese Academy of Sciences, Beijing 100049, China

${ }^{c}$ Key Laboratory of Petroleum Resources, Gansu Province / CAS Key Laboratory of Petroleum Resources Research, Institute of Geology and Geophysics, Chinese Academy of Sciences, Lanzhou 730000, China.E-mail: fanqh@lzb.ac.cn

${ }^{d}$ Beijing Synchrotron Radiation Facility, Institute of High Energy Physics, Chinese Academy of Sciences, Beijing 100049, China

${ }^{e}$ State Key Laboratory of Catalysis, Dalian Institute of Chemical Physics, Chinese Academy of Sciences, China

$\uparrow$ Electronic supplementary information (ESI) available. See DOI: $10.1039 / \mathrm{c} 6 \mathrm{ta} 10016 \mathrm{c}$
High efficiency and inexpensive sorbents for $\mathrm{Cs}^{+}$are therefore highly desirable.

Prussian blue analogues (PBAs), which are used in catalysis $^{12-14}$ and gas storage, ${ }^{\mathbf{1 5 , 1 6}}$ have an open, zeolite-like structure and are constructed by octahedral $\left[\mathrm{M}^{\prime}(\mathrm{CN})_{6}\right]^{n-}$ anionic groups bridged by $\mathrm{M}^{n+}$ ions. ${ }^{17,18}$ PBAs are promising sorbents for metal ions because cations can enter into their small channels and intercalate into the interstitial sites of the porous framework. ${ }^{19}$ The size of these channels $(0.32 \mathrm{~nm})^{\mathbf{2 0}}$ is consistent with the hydrated radius of the $\mathrm{Cs}^{+}$ion $(0.329 \mathrm{~nm}),{ }^{21}$ which has resulted in growing interest in the application of PBAs to the selective uptake of $\mathrm{Cs}^{22,23}$ However, previous work has concentrated on bulk PBAs, which have small surface areas and long diffusion time. The species of $\mathbf{M}$ and $\mathbf{M}^{\prime}$ not only affect the morphology of the PBA, but also the porous structure and interactions with guest molecules, leading to opportunities to tune the sorption performance of the PBA. For example, five $\mathrm{M}-\mathrm{Fe} / \mathrm{chitin}$ composites were synthesized by Guibal et al. ${ }^{26}$ and showed varied adsorption performances for Cs. Long et $a l^{15}$ also demonstrated that adsorbates can interact with the $\mathrm{M}^{2+}$ ions, enhancing the adsorption capacity by changing the species of $\mathbf{M}$ in $\mathrm{M}$-Co PBAs. $\mathrm{Cu}-\mathrm{Co}$ and Co-Co PBAs have been observed to show double adsorption capacity for ammonia of Fe-Fe Prussian blue. Although most efforts have concentrated on using MFe@support composites for Cs sorption, ${ }^{24-27}$ M-Co PBAs have also been reported to adsorb Cs. ${ }^{28}$ Mekhail et al. ${ }^{29}$ confirmed that the nature of $\mathrm{M}^{\mathrm{II}}$ has an effect on the uptake of Cs of $\mathrm{M}-\mathrm{Co}$ 
PBAs. Considering their excellent properties as adsorbents for organic dyes ${ }^{\mathbf{3 0}}$ and heavy metal ions, ${ }^{31}$ the synthesis of nanometer-sized $\mathrm{M}$-Co PBAs with both controllable and tunable morphologies may offer new insights into optimizing their sorption properties. Zn-Co PBA is a 3D double metal cyanide with an excellent catalytic performance in ring-opening polymerization reactions and the adsorption of organic pollutants. $^{32-36}$ However, its application in Cs sorption requires further investigation.

Despite the development of various methods for the morphologically controlled synthesis of PBAs-including hydrothermal, ${ }^{37}$ reverse microemulsion ${ }^{38}$ and chemical etching methods ${ }^{39,40}$ - facile and environmentally friendly approaches require further exploration. We previously reported a facile approach to fabricate $\mathrm{M}(\mathrm{M}=\mathrm{Fe}, \mathrm{Co}, \mathrm{Mn})$-doped $\mathrm{Fe}_{x} \mathrm{M}_{1-x}$ $\left[\mathrm{Co}(\mathrm{CN})_{6}\right]\left(\mathrm{Fe}_{x} \mathrm{M}_{1-x}-\mathrm{Co}\right)$ PBAs with well-controlled morphologies by simply tuning the composition of $\mathrm{M}$. The $\mathrm{Fe}_{0.5} \mathrm{Zn}_{0.5}-\mathrm{Co}$ nanospheres inherited their large size from the Fe-Co PBA and a round shape from the $\mathrm{Zn}-\mathrm{Co}$ PBA. However, whether a regular change in the morphology of $\mathrm{Fe}_{x} \mathrm{Zn}_{1-x}$-Co PBAs could be realized by changing the ratio of $\mathrm{Zn}: \mathrm{Fe}$ requires further investigation.

We report here the synthesis of a series of $\mathrm{Fe}_{x} \mathrm{Zn}_{1-x}-\mathrm{Co}$ PBAs with fine-tuned morphologies by simply modulating the $\mathrm{Zn}: \mathrm{Fe}$ ratio. The morphologies and textural properties of the prepared $\mathrm{Fe}_{x} \mathrm{Zn}_{1-x}$-Co PBAs were characterized by a number of techniques. The $\mathrm{Fe}_{x} \mathrm{Zn}_{1-x}$-Co PBAs were developed as adsorbents for the selective uptake of $\mathrm{Cs}^{+}$. The sorption performances of the $\mathrm{Fe}_{x} \mathrm{Zn}_{1-x}-\mathrm{Co}$ PBAs were systematically determined and were shown to increase as the $\mathrm{Zn}$ : Fe ratio increased. The kinetic and sorption isotherms for the uptake of cesium into the $\mathrm{Zn}-\mathrm{Co}$ PBA, which was the most effective adsorbent, was investigated further. The sorption capacity of the $\mathrm{Zn}-\mathrm{Co}$ PBA was comparable with the best Cs adsorbents reported previously. Based on the quantitative correlation between the concentration of ions released from the PBAs and the $\mathrm{Cs}^{+}$ions adsorbed, a novel $\mathrm{Zn}^{2+}$ modulated $\mathrm{Cs}^{+}$sorption model was proposed and used to explain the better adsorption performance of the $\mathrm{Zn}$-Co PBA compared with the Fe-Co PBA.

\section{Experimental section}

\subsection{Materials and chemicals}

Potassium hexacyanocobaltate(III) $\left(\mathrm{K}_{3}\left[\mathrm{Co}(\mathrm{CN})_{6}\right]\right.$, 98\%) was purchased from Beijing J\&K (China). Ferrous chloride tetrahydrate $\left(\mathrm{FeCl}_{2} \cdot 4 \mathrm{H}_{2} \mathrm{O}, \mathrm{AR}\right)$ and cesium chloride (CsCl, AR) were purchased from Aladdin (China). Zinc nitrate hexahydrate $\left(\mathrm{Zn}\left(\mathrm{NO}_{3}\right)_{2} \cdot 6 \mathrm{H}_{2} \mathrm{O}, \mathrm{AR}\right)$ was purchased from Shanghai Chemical Factory (China). Poly(vinylpyrrolidone) $(M=1000-1300000 \mathrm{~g}$ $\mathrm{mol}^{-1}$ ) was purchased from Tianjin Kermel Chemical Reagent (China). All chemical reagents were used as-received without further purification.

\subsection{Synthesis}

The preparation of the $\mathrm{Fe}_{x} \mathrm{Zn}_{1-x}$-Co PBAs was based on our previously reported concept of copolymer co-morphology using a simple co-precipitation method. ${ }^{41}$ In a typical synthesis procedure, measured amounts of $\mathrm{Zn}\left(\mathrm{NO}_{3}\right)_{2} \cdot 6 \mathrm{H}_{2} \mathrm{O}$ and $\mathrm{FeCl}_{2}$ - $4 \mathrm{H}_{2} \mathrm{O}$ (9 mM in total) were dissolved with stirring in a $30 \mathrm{~g} \mathrm{~L}^{-1}$ poly(vinylpyrrolidone) solution to obtain a transparent solution. An equal volume of an aqueous solution $5 \mathrm{mM} \mathrm{K}_{3}\left[\mathrm{Co}(\mathrm{CN})_{6}\right]$ was added dropwise with vigorous stirring. The mixture was stirred for a further $30 \mathrm{~min}$ and then aged for $20 \mathrm{~h}$. The products were collected by centrifugation, washed three times with ultrapure water and ethanol, followed by drying at $60{ }^{\circ} \mathrm{C}$ for $20 \mathrm{~h}$.

\subsection{Characterization}

Wide-angle powder X-ray diffraction (XRD) patterns were obtained using a PANalytical X'Pert-Pro Super diffractometer equipped with a $\mathrm{Cu} \mathrm{K} \alpha$ radiation source $(\lambda=0.15406 \mathrm{~nm})$, operating at $40 \mathrm{mV}$ and $40 \mathrm{~mA}$. Structural refinements were conducted with the Rietveld method using FULLPROF software on the XRD data. The chemical compositions were analyzed using Thermo IRIS Intrepi II XSP inductively coupled plasma optical emission spectrometry (ICP-OES). As a result of the good stability of Fe-Co PBA in acidic solution, a new method was used to dissolve the as-prepared samples before ICP-OES analysis. ZnCo PBA was easily dissolved in aqua regia, whereas the Fe-Co PBA was pretreated with a $1 \mathrm{~mol} \mathrm{~L}^{-1} \mathrm{NaOH}$ solution to give the corresponding oxide before dissolution in a $1 \mathrm{~mol} \mathrm{~L}^{-1} \mathrm{HCl}$ solution.

SEM images were recorded using a JEOL JSM-7800F scanning electron microscope. TEM measurements were made with a JEOL JEM-2100F high-resolution transmission electron microscope. Elemental analysis was conducted before and after adsorption using the energy-dispersive X-ray spectrometer attached to the transmission electron microscope. The specific surface areas were measured by the Brunauer-Emmett-Teller (BET) $\mathrm{N}_{2}$ adsorption-desorption method on a Micromeritics ASAP 2010 instrument at $77 \mathrm{~K}$. The pore size distributions were determined using the Horvath-Kawazoe method.

Room temperature ${ }^{57} \mathrm{Fe}$ Mössbauer spectra were recorded using a proportional counter and a Topologic 500A spectrometer with ${ }^{57} \mathrm{Co}(\mathrm{Rh})$ as a $\gamma$-ray radioactive source. $\mathrm{Zn}$ K-edge extended X-ray absorption fine structure spectrometry (EXAFS) was performed at the BL14W1 beamline of the Shanghai Synchrotron Radiation Facility. A Si (311) double-crystal monochromator was used to monochromatize the incident beam while reducing the high harmonics of the monochromatic beam. EXAFS data analysis was performed using the Demeter package following the conventional procedure: background removal, normalization and Fourier transformation of EXAFS oscillations. ${ }^{42}$

\subsection{Adsorption experiments}

The sorption behavior of elemental, stable Cs $\left({ }^{133} \mathrm{Cs}\right)$ on the synthesized PBAs was studied. All the Cs extraction experiments were performed in batch solutions with stirring at $298 \mathrm{~K}$. The concentrations of $\mathrm{Cs}^{+}$and $\mathrm{K}^{+}$were determined using a ThermoFisher ICS-5000 ion chromatograph with a CS12A analytical column and a CG12A suppressor column.

In the sorption kinetics studies, $100 \mathrm{mg}$ of the adsorbents were added to $100 \mathrm{~mL}$ of an aqueous solution of $0.001 \mathrm{~mol} \mathrm{~L}^{-1}$ 
$\mathrm{CsCl}$ with strong agitation. At given reaction time intervals, 2.0 $\mathrm{mL}$ samples were withdrawn and immediately centrifuged before the concentrations of the remaining $\mathrm{Cs}^{+}$and $\mathrm{K}^{+}$were measured. For the adsorption isotherm studies, $20 \mathrm{mg}$ of $\mathrm{Zn}-\mathrm{Co}$ PBA were dispersed with stirring in $20 \mathrm{~mL}$ of $\mathrm{CsCl}$ solutions with initial $\mathrm{Cs}^{+}$concentrations ranging from 0.0004 to $0.004 \mathrm{~mol} \mathrm{~L}^{-1}$ for 2 weeks, the time at which equilibrium was always reached. The adsorbents were then separated and the concentrations of residual $\mathrm{Cs}^{+}$were determined.

\section{Results and discussion}

\subsection{Synthesis and characterization}

A series of $\mathrm{Fe}_{x} \mathrm{Zn}_{1-x}-\mathrm{Co}(x=0,0.2,0.4,0.6,0.8,1)$ PBAs were synthesized by simply mixing $\mathrm{FeCl}_{2}$ and $\mathrm{Zn}\left(\mathrm{NO}_{3}\right)_{2}$ with $\mathrm{K}_{3}\left[\mathrm{Co}(\mathrm{CN})_{6}\right]$ and tuning the input ratio of $\mathrm{Zn}$ to Fe. The actual chemical compositions of the as-prepared $\mathrm{Fe}_{x} \mathrm{Zn}_{1-x}-\mathrm{Co}$ PBAs were analyzed by ICP-OES (Table 1). Despite the excess amounts of $\mathrm{M}^{2+}$ used, the products obtained still contained soluble Prussian blue with different amounts of $\mathrm{K}^{+}$remaining in the structure. ${ }^{18,43}$ The $\mathrm{K}^{+}$content increased with increasing amounts of $\mathrm{Zn}$, probably because $\mathrm{Zn}$ was less strongly coordinated with $\mathrm{N}$ than Fe. The crystalline structures of the products were examined by XRD (Fig. 1). The relative intensity and peak positions were well indexed to the face-centered cubic structure of $\mathrm{Fe}_{3}\left[\mathrm{Co}(\mathrm{CN})_{6}\right]_{2}-$ $\cdot 12 \mathrm{H}_{2} \mathrm{O}$ (JCPDS no. 89-3736), where no impurity peak was detected, further suggesting the phase purity of the products. As the $\mathrm{Zn}$ : Fe ratio increased, the positions of the diffraction peaks shifted slightly toward higher angles as a result of the larger diameter of high-spin $\mathrm{Fe}^{2+}$ relative to $\mathrm{Zn}^{2+} \cdot{ }^{44}$ Based on the (200) diffraction peak, the average crystalline size of the series of $\mathrm{Fe}_{x^{-}}$ $\mathrm{Zn}_{1-x}$-Co PBAs was calculated using Scherrer's equation (Table 1).

Fig. 2 shows SEM images of the as-prepared $\mathrm{Fe}_{x} \mathrm{Zn}_{1-x}-\mathrm{Co}$ PBAs. Gradual changes were observed in the morphology with increases in the $\mathrm{Zn}$ : Fe ratio. Without any $\mathrm{Zn}$ (Fig. 2a), the FeCo PBA had a truncated spherical shape with a clear crosssection, similar to that reported previously. ${ }^{41}$ When $20 \%$ of the Fe was substituted by $\mathrm{Zn}$, the area of the cross-section decreased. With further increases in the $\mathrm{Zn}$ content, the nanoparticles became increasingly spherical and decreased in size (Fig. 2b-f). These results further confirmed the copolymer comorphology phenomenon reported previously, in which

Table 1 Chemical composition and average crystallite size of the asprepared $\mathrm{Fe}_{x} \mathrm{Zn}_{1-x}-\mathrm{Co} \mathrm{PBAs}$

\begin{tabular}{lll}
\hline Sample & Chemical composition ${ }^{a}$ & $\begin{array}{l}\text { Average crystallite } \\
\text { size }(\mathrm{nm})\end{array}$ \\
\hline $\mathrm{Fe}-\mathrm{Co}$ & $\mathrm{K}_{0.05} \mathrm{Fe}_{2.94}\left[\mathrm{Co}(\mathrm{CN})_{6}\right]_{2}$ & 133.9 \\
$\mathrm{Fe}_{0.8} \mathrm{Zn}_{0.2}-\mathrm{Co}$ & $\mathrm{K}_{0.07} \mathrm{Fe}_{2.45} \mathrm{Zn}_{0.49}\left[\mathrm{Co}(\mathrm{CN})_{6}\right]_{2}$ & 133.9 \\
$\mathrm{Fe}_{0.6} \mathrm{Zn}_{0.4}-\mathrm{Co}$ & $\mathrm{K}_{0.35} \mathrm{Fe}_{1.88} \mathrm{Zn}_{0.86}\left[\mathrm{Co}(\mathrm{CN})_{6}\right]_{2}$ & 114.8 \\
$\mathrm{Fe}_{0.4} \mathrm{Zn}_{0.6}-\mathrm{Co}$ & $\mathrm{K}_{0.43} \mathrm{Fe}_{1.30} \mathrm{Zn}_{1.30}\left[\mathrm{Co}(\mathrm{CN})_{6}\right]_{2}$ & 114.8 \\
$\mathrm{Fe}_{0.2} \mathrm{Zn}_{0.8}-\mathrm{Co}$ & $\mathrm{K}_{0.62} \mathrm{Fe}_{0.70} \mathrm{Zn}_{1.82}\left[\mathrm{Co}(\mathrm{CN})_{6}\right]_{2}$ & 89.3 \\
$\mathrm{Zn}-\mathrm{Co}$ & $\mathrm{K}_{1.48} \mathrm{Zn}_{2.26}\left[\mathrm{Co}(\mathrm{CN})_{6}\right]_{2}$ & 73.1
\end{tabular}

${ }^{a}$ As shown by Mössbauer spectra, the first four samples contained both $\mathrm{Fe}(\mathrm{II})$ and $\mathrm{Fe}(\mathrm{III})$.

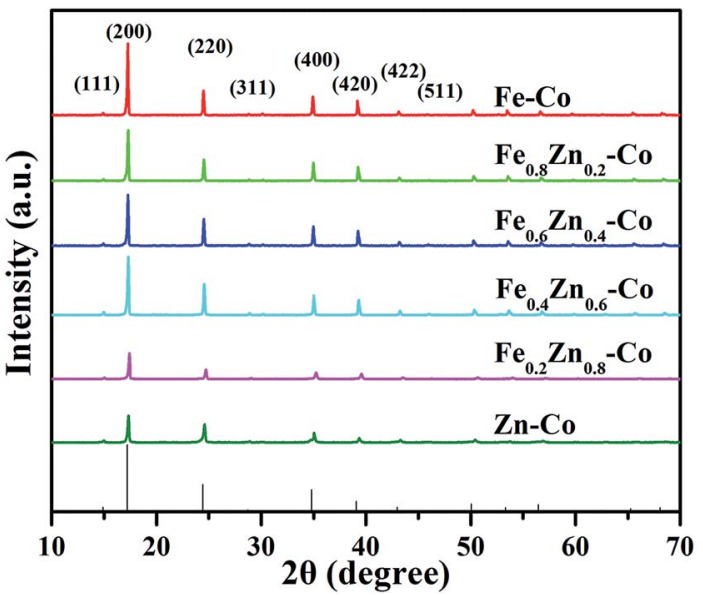

Fig. 1 XRD patterns of the synthesized $\mathrm{Fe}_{x} \mathrm{Zn}_{1-x}-\mathrm{Co}$ PBAs.
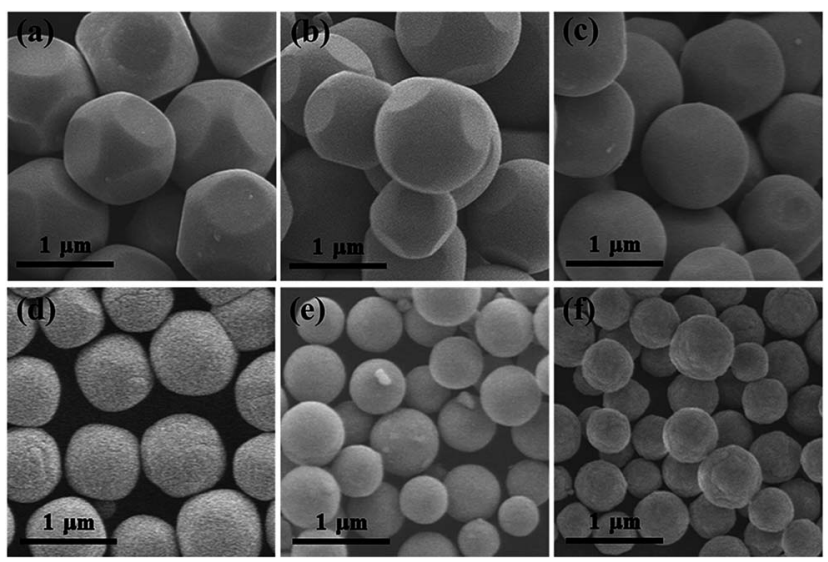

Fig. 2 SEM images of $\mathrm{Fe}_{x} \mathrm{Zn}_{1-x}-\mathrm{Co} \mathrm{PBAs}$. (a) Fe-Co PBA; (b) $\mathrm{Fe}_{0.8} \mathrm{Zn}_{0.2}-\mathrm{Co} P B A ;$ (c) $\mathrm{Fe}_{0.6} \mathrm{Zn}_{0.4}$-Co PBA; (d) $\mathrm{Fe}_{0.4} \mathrm{Zn}_{0.6}-\mathrm{Co}$ PBA; (e) $\mathrm{Fe}_{0.2} \mathrm{Zn}_{0.8}-\mathrm{Co} P B A$; and (f) $\mathrm{Zn}-\mathrm{Co} P B A$.

a solid solution of $\mathrm{Zn}-\mathrm{Co}$ and $\mathrm{Fe}-\mathrm{Co}$ PBAs inherited the morphological features of the parent PBAs. ${ }^{41}$ The surface of the PBAs became rougher as the $\mathrm{Zn}$ content increased, corresponding to the lower crystallinity and smaller crystal size observed by XRD.

Full $\mathrm{N}_{2}$ sorption isotherms were collected to investigate the specific surface area and pore size of the adsorbents. Fig. 3a shows the adsorption-desorption results for $\mathrm{Zn}$-Co PBA and the corresponding Horvath-Kawazoe pore size distribution curve. The nanoparticles displayed a steep $\mathrm{N}_{2}$ gas uptake in the low pressure region, characteristic of a typical type I isotherm ${ }^{45}$ according to the IUPAC classification, indicating the microporous nature of the material. The other five samples showed isotherms with a similar shape to Zn-Co PBA (Fig. S1 $\dagger$ ). The textual properties of the six samples are listed in Table S1. $\uparrow$ Except for Fe-Co PBA, the BET surface areas became lower as the ratio of $\mathrm{Zn}: \mathrm{Fe}$ increased, probably due to a reduction in the $\left[\mathrm{Co}(\mathrm{CN})_{6}\right]^{3-}$ vacancies.

All these results demonstrate that the as-prepared $\mathrm{Fe}_{x} \mathrm{Zn}_{1-x^{-}}$ Co PBAs, with their well-controlled morphology and large surface area as well as suitable pore size, are potential adsorbents for the removal of Cs from water. 
(a)
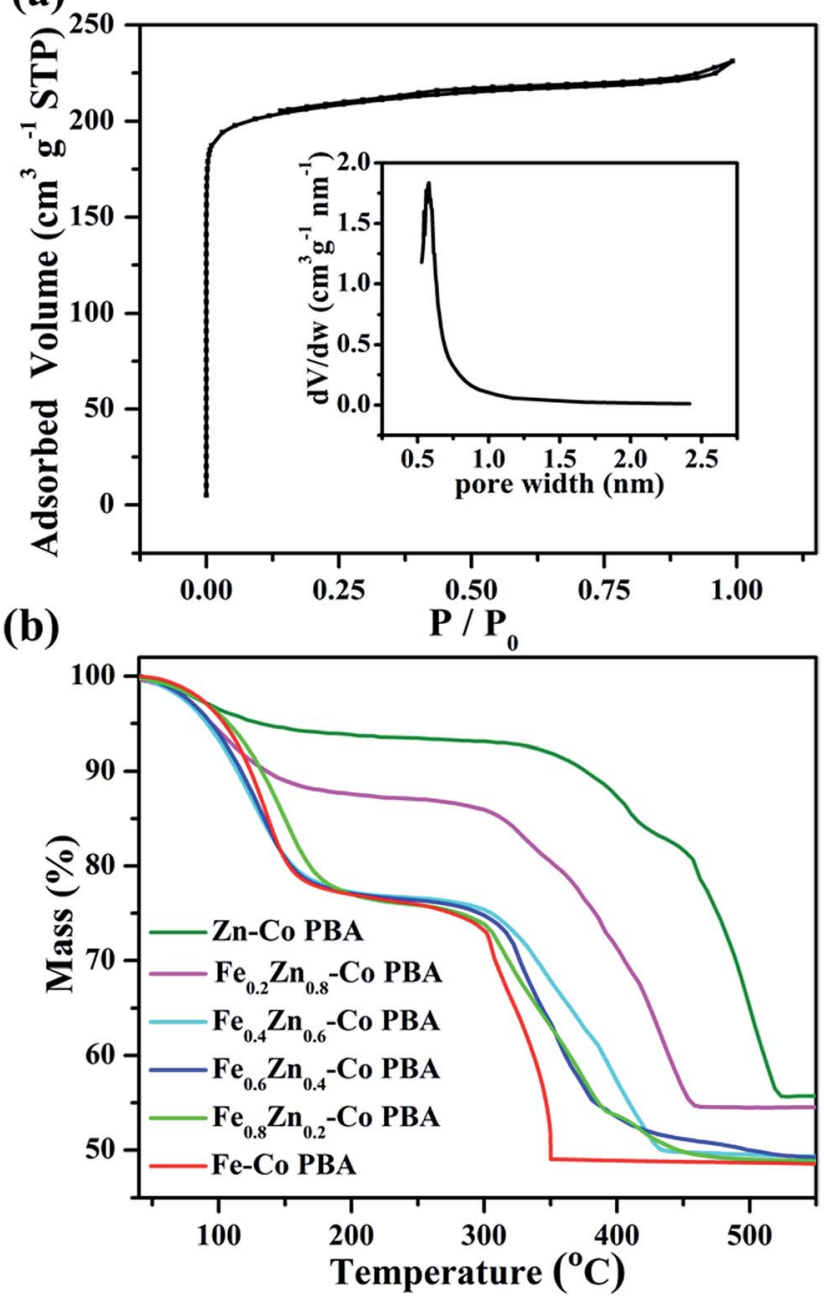

Fig. 3 (a) $\mathrm{N}_{2}$ adsorption-desorption isotherm of $\mathrm{Zn}-\mathrm{Co}$ PBA (inset, pore size distribution). (b) Thermogravimetric profiles of the series of synthesized $\mathrm{Fe}_{x} \mathrm{Zn}_{1-x}-\mathrm{Co}$ PBAs.

Crystalline water molecules located at the interstitial sites also influence the porous structures. Fig. $3 \mathrm{~b}$ shows the results of the thermogravimetric analysis of the series of $\mathrm{Fe}_{x} \mathrm{Zn}_{1-x}-\mathrm{Co}$ PBAs and indicates that the six materials all had two stages of decomposition. Using Zn-Co PBA as an example (Fig. S2 $\dagger$ ), the nanospheres showed a weight loss of about $6 \%$ between room temperature and $200{ }^{\circ} \mathrm{C}$ as a result of the removal of crystalline water. The weight loss in the second stage, accompanied by a dramatic emission of heat at 350 and $520^{\circ} \mathrm{C}$, can be attributed to the oxidation of cyanide and residual surfactants. Despite similar decomposition processes, the mass of crystalline water molecules increased with the $\mathrm{Fe}: \mathrm{Zn}$ ratio, probably because $\mathrm{K}^{+}$ ions occupied the same site $(0.25,0.25,0.25)$ as the $\mathrm{O}$ atoms. ${ }^{43}$ As a result, higher $\mathrm{K}$ contents led to a lower proportion of water molecules in the crystal structure.

\subsection{Cs sorption properties}

The uptake capacity for Cs of the as-prepared $\mathrm{Fe}_{x} \mathrm{Zn}_{1-x}-\mathrm{Co}$ PBAs at different contact time is shown in Fig. 4 . All the synthesized $\mathrm{Fe}_{x} \mathrm{Zn}_{1-x}$-Co PBAs had the ability to adsorb Cs and the uptake of

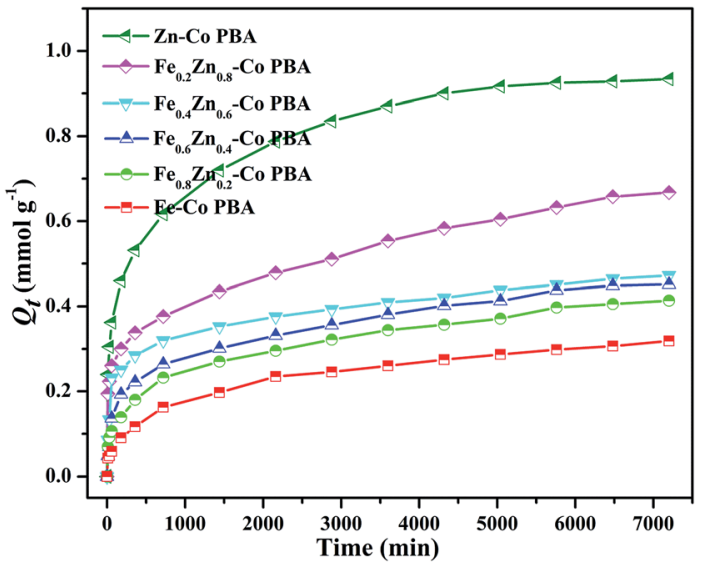

Fig. 4 Amounts of $\mathrm{Cs}$ adsorbed onto $\mathrm{Fe}_{x} \mathrm{Zn}_{1-x}-\mathrm{Co}$ PBAs at different stirring times.

Cs depended on the composition of the $\mathrm{Fe}_{x} \mathrm{Zn}_{1-x}$-Co PBA. The substitution of $\mathrm{Zn}$ for Fe enhanced the sorption performance of the PBAs. The $\mathrm{Zn}-\mathrm{Co}$ PBA was able to remove $95 \%$ of the $\mathrm{Cs}^{+}$ ions from solutions with $\mathrm{Cs}^{+}$concentration up to $0.001 \mathrm{M}$; however, the removal efficiency was only $34 \%$ when Fe-Co PBA was used. Considering the smaller surface area of $\mathrm{Zn}-\mathrm{Co}$ PBA compared with the other $\mathrm{Fe}_{x} \mathrm{Zn}_{1-x}$-Co PBAs $(0<x<1)$, the species of the doped transition metal may influence the ionexchange process with the $\mathrm{Cs}^{+}$ions and enhance the sorption capability.

3.2.1. Sorption kinetics. The uptake kinetics of $\mathrm{Zn}-\mathrm{Co}$ PBA was investigated as a model to further illustrate the sorption behavior. The change in sorption with time was fitted by a pseudo-second-order kinetic model ${ }^{46}$ based on the assumption that chemisorption was the rate-determining step as is the case in most reactions involving sorption on solid substrates. ${ }^{22}$ The linearized form of the model can be expressed as:

$$
\begin{aligned}
\frac{t}{Q_{t}} & =\frac{1}{k_{2} Q_{\mathrm{e}}{ }^{2}}+\frac{t}{Q_{\mathrm{e}}} \\
Q_{t} & =\frac{t}{\frac{1}{k Q_{\mathrm{e}}{ }^{2}}+\frac{t}{Q_{\mathrm{e}}}}
\end{aligned}
$$

where $Q_{t}$ is the amount of adsorbate adsorbed per unit weight of adsorbent $\left(\mathrm{mmol} \mathrm{g}^{-1}\right)$ at time $t$. The second-order rate constant $\left(k_{2}\right)$ and equilibrium $\mathrm{Cs}^{+}$sorption capacity $Q_{\mathrm{e}}$ could be calculated from the model. Fig. 5a shows that the kinetic data could be well fitted into two stages, suggesting a transformation of the dominant mechanism during the process. We describe here the process using a bi-pseudo-second-order kinetic model:

$$
Q_{t}=\frac{t}{\frac{1}{k_{1} Q_{\mathrm{e} 1}{ }^{2}}+\frac{t}{Q_{\mathrm{e} 1}}}+\frac{t}{\frac{1}{k_{2} Q_{\mathrm{e} 2}{ }^{2}}+\frac{t}{Q_{\mathrm{e} 2}}}
$$

where $k_{1}, k_{2}, Q_{\mathrm{e} 1}$ and $Q_{\mathrm{e} 2}$ are the rate constants and equilibrium $\mathrm{Cs}^{+}$sorption capacities during processes 1 and 2, respectively. The rate constants of the two processes were quantified as 0.3773 and $0.0012 \mathrm{~g} \mathrm{mmol}^{-1} \mathrm{~min}^{-1}$ from the best fits to the 

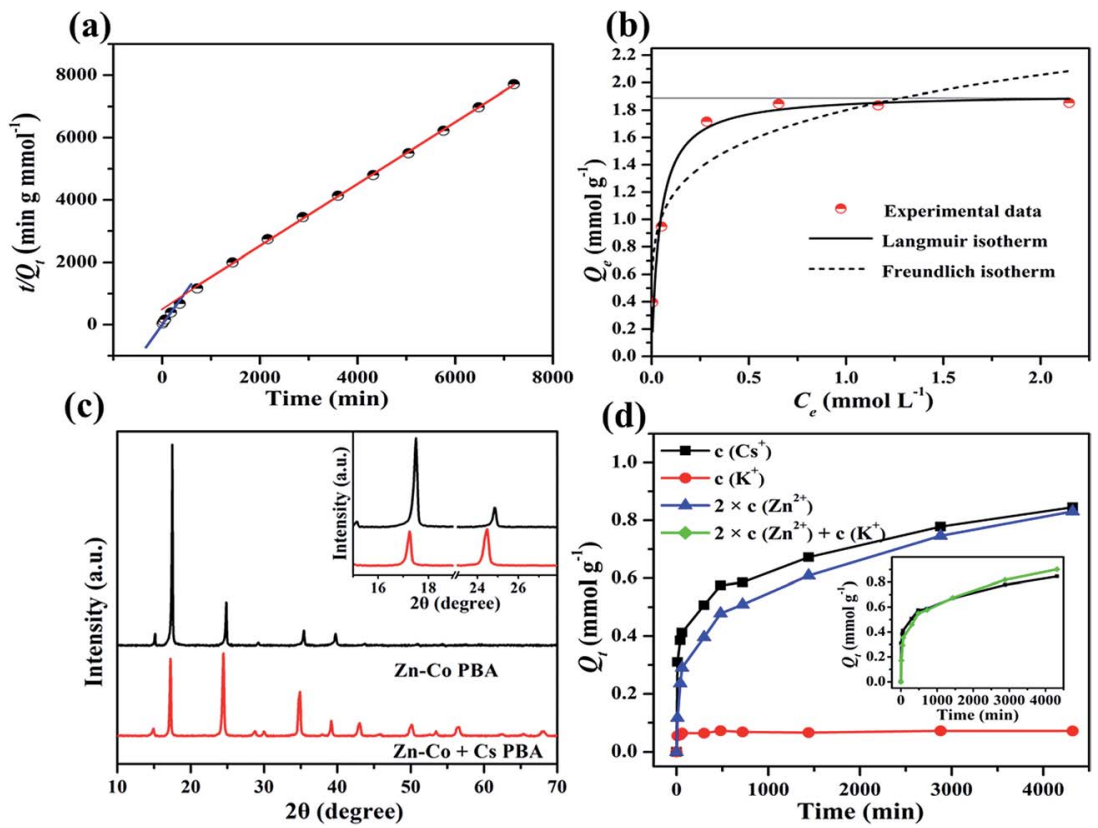

Fig. 5 (a) Pseudo-second-order kinetic plots for adsorption of Cs onto Zn-Co PBA at 298 K. (b) Experimental data fitted with Langmuir and Freundlich adsorption isotherm models. (c) XRD patterns of $\mathrm{Zn}-\mathrm{Co}$ PBA before and after adsorption. (d) Concentrations of $\mathrm{K}^{+}$and $\mathrm{Zn}^{2+}$ released and $\mathrm{Cs}^{+}$adsorbed at different time (concentration of $\mathrm{Zn}^{2+}$ is doubled for direct comparison with $\mathrm{K}^{+}$and $\mathrm{Cs}^{+}$).

observed data. The two stages in the Cs uptake process were probably due to the transformation of the dominant mechanism, as discussed later in this paper.

3.2.2. Adsorption isotherm. Fitting the experimental data with isotherm models is an effective way of determining the maximum sorption capacity and understanding the sorption mechanism. Adsorption isotherms were therefore used to describe the equilibrium distribution of Cs between the adsorbent and the liquid phase. The increase in the adsorption capacity for Cs with different initial Cs concentrations is plotted in Fig. 5b. The adsorption data were analyzed according to the well-known Langmuir and Freundlich isotherm models. ${ }^{47,48}$ The nonlinear form of the Langmuir model can be written as:

$$
q_{\mathrm{e}}=q_{\max } \frac{K C_{\mathrm{e}}}{1+K C_{\mathrm{e}}}
$$

where $C_{\mathrm{e}}$ is the equilibrium concentration of the adsorbate $(\mathrm{mg}$ $\left.\mathrm{L}^{-1}\right), K$ is a constant related to the affinity between the adsorbent and adsorbate, and $q_{\mathrm{e}}$ and $q_{\mathrm{max}}$ are the equilibrium adsorption capacity and monolayer maximum adsorption capacity $\left(\mathrm{mmol} \mathrm{g}^{-1}\right)$, respectively. The isotherm was well fitted by the Langmuir model with $R^{2}=0.96$ (Fig. 5b), indicating that the adsorption of $\mathrm{Cs}^{+}$could be well described by the Langmuir model. The Freundlich model was a poor fit for the data (Fig. 5b). These results suggest that the sorption of $\mathrm{Cs}^{+}$most probably occurs on a homogeneous surface without any lateral interaction between the adsorbed molecules and the PBAs. The chemisorption properties of the Langmuir model also indicate that the strongly adsorbed Cs interacts with the PBA framework. The fitted parameters and correlation coefficients for both models are given in Table S2. $\dagger$ The maximum sorption capacity of the $\mathrm{Zn}$-Co PBA was $1.92 \mathrm{mmol} \mathrm{g}^{-1}$, which is comparable with the reported adsorption capacity for Cs in previous reports (Table 2).

3.2.3. Stability. Leaching of hexacyanocobaltate fragments into treated water is undesirable and therefore the resistance of the materials to leaching was studied. The concentrations of Co in solution after adsorption by the materials were only 0.045 , $0.015,0.014,0.003$ and $0.003 \%$, respectively. The crystal structure was maintained, as seen in the XRD patterns of $\mathrm{Fe}_{x} \mathrm{Zn}_{1-x^{-}}$ Co PBAs after adsorption (Fig. S4 $\dagger$ ), indicating that no structural collapse occurred during sorption. The high Cs sorption capacity and good stability mean that the $\mathrm{Zn}-\mathrm{Co}$ PBA is a potential candidate for Cs sorption.

\subsection{Characterization after adsorption}

The XRD patterns of $\mathrm{Zn}$-Co PBA before and after sorption are compared in Fig. $5 \mathrm{c}$. The slight shift in the diffraction peaks toward lower $2 \theta$ after $\mathrm{Cs}^{+}$sorption could be ascribed to the larger ionic radius of $\mathrm{Cs}^{+}$compared with $\mathrm{K}^{+}$. A similar shift was also observed in the diffraction patterns of other $\mathrm{Cs}^{+}$-exchanged $\mathrm{Fe}_{x} \mathrm{Zn}_{1-x}$-Co products, with a larger uptake inducing larger structural changes (Fig. S4 $\dagger$ ). The intensity ratio of the (200) and (220) reflections changed significantly after the adsorption of large amounts of Cs, indicating the insertion of Cs into the crystal channels. ${ }^{19}$

\subsection{Adsorption mechanism}

The mechanism of $\mathrm{Cs}^{+}$sorption by PBAs is controversial in terms of which positive ions exchange with $\mathrm{Cs}^{+}{ }^{+}{ }^{27,52,53} \mathrm{As} \mathrm{Cs}^{+}$is widely recognized to adsorb on PBAs via $\mathrm{K}^{+}$or proton-exchange processes, ${ }^{27,53,54}$ we investigated the $\mathrm{pH}$ of the solutions after adsorption (Table $\mathrm{S} 3 \dagger$ ). The small decrease in the $\mathrm{pH}$ indicated 
Table 2 Cesium sorption capacities of some reported adsorbents

\begin{tabular}{lll}
\hline Material & $Q_{\max }\left(\mathrm{mg} \mathrm{g}^{-1}\right)$ & Reference \\
\hline Hollow PB nanoparticles & 262 & 40 \\
Commercial PB nanoparticles & 29.3 & 40 \\
Graphene foam/PB composite & 18.67 & 23 \\
Copper hexacyanoferrate & 204.8 & 49 \\
Silicododecamolybdate & 134 & 50 \\
CoHCF, CuHCF, ZnHCF (hexacyanoferrates)@silica monolith & 24.5 & 51 \\
Zn-Co PBA & $255\left(1.92 \mathrm{mmol} \mathrm{g}^{-1}\right)$
\end{tabular}

that few protons were exchanged into the solution during the sorption of $\mathrm{Cs}^{+}$by $\mathrm{Zn}-\mathrm{Co} \mathrm{PBA}$, confirming that proton exchange is not the main pathway for $\mathrm{Cs}^{+}$sorption. The concentration of $\mathrm{K}^{+}$released into solution was recorded by ion chromatography (Fig. 5d, red line). Except for a dramatic increase during the first 10 minutes, the concentration of $\mathrm{K}^{+}$fluctuated around $9 \times$ $10^{-6} \mathrm{~mol} \mathrm{~L}^{-1}$, probably due to instrumental errors. The concentration of $\mathrm{Zn}^{2+}$ released into solution over a particular time interval was investigated by ICP-OES and the concentration of $\mathrm{Zn}^{2+}$ showed a quantitative correlation with the amount of $\mathrm{Cs}^{+}$adsorbed. Fig. $5 \mathrm{~d}$ (blue line) shows that a quantitative value of $2 \times c\left(\mathrm{Zn}^{2+}\right)$, equal to the amount of $\mathrm{Cs}^{+}$exchanged with $\mathrm{Zn}^{2+}$ according to charge conservation, showed a similar trend in variation with the quantity of $\mathrm{Cs}^{+}$adsorbed. The sum (green line) of $\mathrm{K}^{+}$and the value of the converted $\mathrm{Zn}^{2+}$ concentration is consistent with the amount of $\mathrm{Cs}^{+}$adsorbed (black line).

Based on these results, a $\mathrm{Zn}^{2+}$-modulated $\mathrm{Cs}^{+}$sorption model was proposed (Fig. 6). The crystal structure model of Zn-Co PBA used was based on the single crystal study by Ludi and Güdel. ${ }^{43}$ The Rietveld structural refinement based on the XRD data was used to elucidate the crystal structure of the material. The fractional atomic coordinates, occupancies and other related parameters are given in Table $\mathrm{S} 4, \uparrow$ based on which the crystal structure of Zn-Co PBA is described in Fig. S5. $\uparrow$ Corresponding to the kinetic dynamic data (Fig. 5a), two adsorption processes can be observed from the proposed model. During the first process, $\mathrm{Cs}^{+}$sorption proceeds mainly through the ion exchange of $\mathrm{K}^{+}$with $\mathrm{Cs}^{+}$, whereas during the second process, $\mathrm{Zn}^{2+}$ is released into solution followed by the entry of $\mathrm{Cs}^{+}$into the channels. The PBA channels carry negative charges after the release of $\mathrm{Zn}^{2+}$, providing the driving force for the entry of $\mathrm{Cs}^{+}$ ions. However, the point at which the quantity of $\mathrm{K}^{+}$begins to stabilize is not consistent with the inflection point of the kinetic curve. This may be because $\mathrm{Cs}^{+}$enters after the $\mathrm{Zn}^{2+}$ is released. The chemical formula of $\mathrm{Zn}-\mathrm{Co}+\mathrm{Cs}$ was determined to be $\mathrm{K}_{0.33} \mathrm{Cs}_{0.86} \mathrm{Zn}_{0.91}\left[\mathrm{Co}(\mathrm{CN})_{6}\right]$ by ICP-OES. As a result, the release of $\mathrm{Zn}^{2+}$ from the crystal was demonstrated to have a crucial role in prompting the sorption of $\mathrm{Cs}^{+}$into the channels, modulating the Cs uptake performance.

The $\mathrm{Zn}-\mathrm{Co}$ and $\mathrm{Zn}-\mathrm{Co}+\mathrm{Cs}$ samples were characterized by $\mathrm{Zn}$ K-edge EXAFS (Fig. 7). The $k^{3}$ weighted EXAFS spectra were fitted over $k=[2,12] \AA^{-1}$ (first shell) and $R=[1,2] \AA$ using the structural model. ${ }^{18}$ We fitted the first shell coordination number, bond distance and corresponding mean square relative displacement around the central absorber Zn (Table 3).

Fig. $7 \mathrm{~b}$ shows that the first peak at $c 1.6 \AA$ corresponds to the $\mathrm{Zn}-\mathrm{N}$ bond. Quantitative fitting revealed that the $\mathrm{Zn}-\mathrm{N}$ bond distance increased from $2.08 \AA$ in $\mathrm{Zn}$-Co PBA up to $2.13 \AA$ in $\mathrm{Zn}-$ $\mathrm{Co}+\mathrm{Cs}$. This increase in the bond distance can be attributed to the expansion of the crystal after the insertion of Cs, in good agreement with XRD results. However, the coordination number varied from 5.2 for $\mathrm{Zn}$-Co PBA to 5.9 for $\mathrm{Zn}-\mathrm{Co}+\mathrm{Cs}$. It is known that $\mathrm{Zn}$ occupies an octahedral site in the cubic lattice and the structure may contain a large number of hexacyanocobaltate vacancies to obtain charge neutrality. As a result, the actual coordination number around $\mathrm{Zn}$ can vary between 2 and $6 .^{33}$ Considering the increase in coordination number after adsorption, we can infer that $\mathrm{Zn}$ atoms coordinated with fewer $\mathrm{N}$ atoms are more likely to be released from the structure and are more favorable for the sorption of Cs. The proposed mechanism can be used to illustrate why the substitution of $\mathrm{Zn}$ for Fe can promote Cs sorption. As an ion with a $\mathrm{d}^{10}$
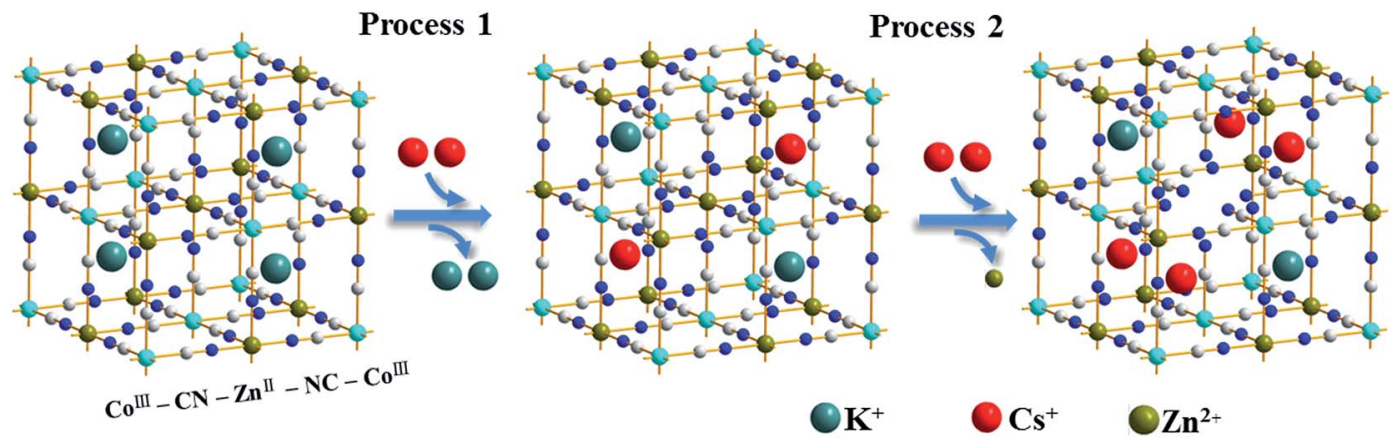

Fig. 6 Schematic diagram of $\mathrm{Zn}^{2+}$-modulated model for Cs sorption in $\mathrm{Zn}$-Co PBA (interstitial and crystal water molecules are omitted for clarity). 
(a)

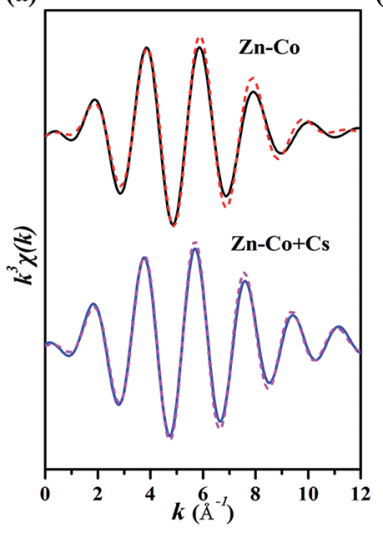

(b)

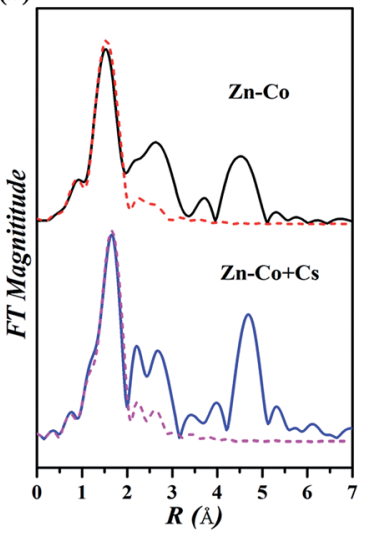

Fig. 7 Fitted and experimental (a) $k^{3}$-weighted $\chi(k)$ spectra for the first shell and (b) Fourier transformed Zn K-edge EXAFS spectra for Zn-Co and $\mathrm{Zn}-\mathrm{Co}+\mathrm{Cs}$ samples. Solid and dashed lines refer to experimental and fitted data $(R=[1,2] \AA)$, respectively.

Table 3 Structural parameters fitted by EXAFS of $\mathrm{Zn}-\mathrm{Co}$ and $\mathrm{Zn}-\mathrm{Co}+$ Cs samples

\begin{tabular}{lllll}
\hline Sample & CN (first shell) & $R($ Zn-N) $(\AA)$ & $\begin{array}{l}\text { Debye-Waller } \\
\text { factor }\end{array}$ & $R$ factor \\
\hline Zn-Co & 5.2 & 2.08 & 0.006 & 0.031 \\
Zn-Co + Cs & 5.9 & 2.13 & 0.006 & 0.022
\end{tabular}

electron configuration, $\mathrm{Zn}^{2+}$ coordinates with $\mathrm{N}$ more weakly than $\mathrm{Fe}^{2+}$, which has empty d orbitals to receive electrons donated from $\mathrm{N}$.

The bond strength of the PBAs was further confirmed by FTIR. The FTIR spectra of the PBAs show a sharp peak at about $2170 \mathrm{~cm}^{-1}$ (Fig. 8), which was assigned to the stretching vibration peak of the bridging cyano group $(-\mathrm{CN})$. With an increase in the $\mathrm{Zn}$ : Fe ratio, the $v(\mathrm{C} \equiv \mathrm{N})$ shifts from $2167 \mathrm{~cm}^{-1}$ to a higher frequency at $2177 \mathrm{~cm}^{-1}$. Previous reports have shown that the wavenumber of this vibration mode is strongly affected by the metal bound to the $\mathrm{CN}$ group. ${ }^{55,56} \mathrm{Zn}$ thus forms
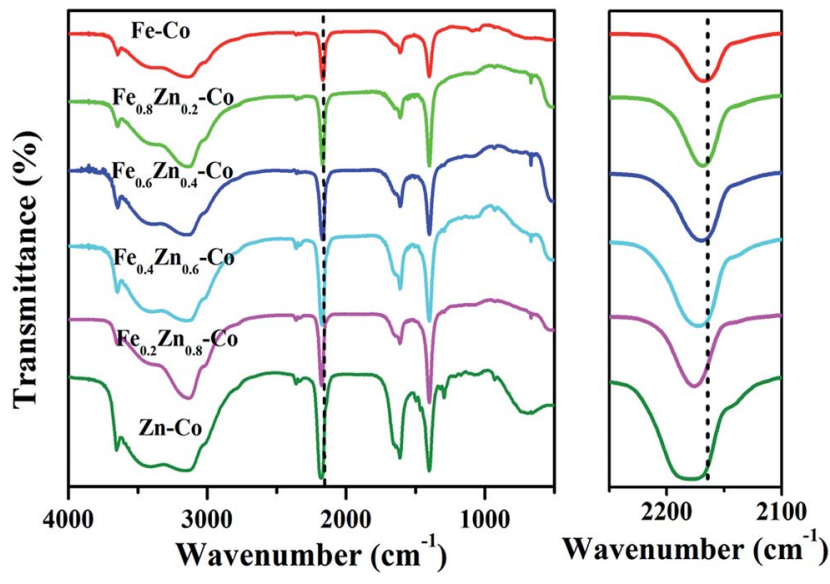

Fig. 8 FTIR spectra of $\mathrm{Fe}_{x} \mathrm{Zn}_{1-x}-\mathrm{Co}$ PBAs.

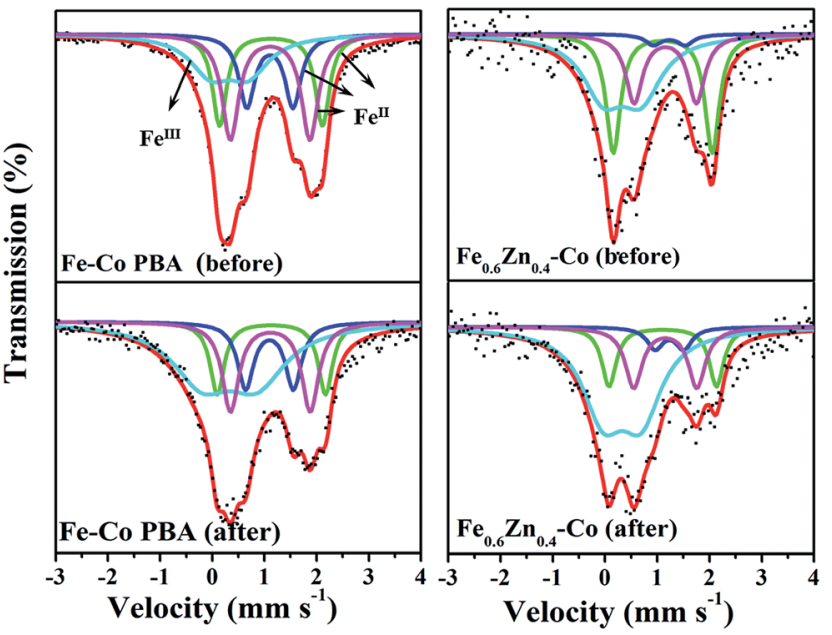

Fig. 9 Room temperature ${ }^{57} \mathrm{Fe}$ Mössbauer spectra of $\mathrm{Fe}-\mathrm{Co}$ and $\mathrm{Fe}_{0.6} \mathrm{Zn}_{0.4}-\mathrm{Co}$ before and after adsorption.

weaker bonds than $\mathrm{Fe}$ with $\left[\mathrm{Co}(\mathrm{CN})_{6}\right]^{3-}$ and is easier to release into solution, promoting the entry of Cs into the PBA channels. ${ }^{19}$

The ${ }^{57} \mathrm{Fe}$ Mössbauer spectra of $\mathrm{Fe}-\mathrm{Co}$ and $\mathrm{Fe}_{0.6} \mathrm{Zn}_{0.4}-\mathrm{Co}$ before and after reaction were measured to investigate the changes in the Fe sites during reaction (Fig. 9). The model used to fit the spectra was the same as in previous work for a similar PBA complex ${ }^{13,19}$ and the relevant parameters are listed in Table S5. $\uparrow$ The three doublets with isomer shifts $(\delta)$ of around $1.1 \mathrm{~mm}$ $\mathrm{s}^{-1}$ were assigned to high-spin Fe(II) species located in different coordination environments, identified by different quadrupole splitting (QS) values. The values of another doublet $(\delta=0.33$ $\mathrm{mm} \mathrm{s}^{-1}, \mathrm{QS}=0.72-1.05 \mathrm{~mm} \mathrm{~s}^{-1}$ ) were consistent with the highspin $\mathrm{Fe}^{3+}$ species. The decrease in the relative peak area of $\mathrm{Fe}^{\mathrm{II}}$ as a result of the oxidization of $\mathrm{Fe}^{\mathrm{II}}$ to $\mathrm{Fe}^{\mathrm{III}}$ after sorption may also result from charge compensation during the release of $\mathrm{Zn}^{2+}$ and $\mathrm{K}^{+}$from the PBAs.

To confirm the general applicability of the $\mathrm{Zn}^{2+}$-modulated $\mathrm{Cs}^{+}$sorption model for $\mathrm{Zn}-\mathrm{Co}$ PBAs, another four PBAs previously reported as adsorbents ( $\mathrm{Mn}-\mathrm{Co}, \mathrm{Co}-\mathrm{Fe}, \mathrm{Ni}-\mathrm{Co}$ and $\mathrm{Cu}-\mathrm{Fe}$ PBAs) were further synthesized and applied as adsorbents for the removal of Cs. Under the same reaction conditions as Zn-Co PBA, the concentrations of the $\mathrm{M}^{\mathrm{A}}$ and $\mathrm{M}^{\mathrm{B}}$ ions released into solution were measured (Table $\mathrm{S} 6 \dagger$ ). The release of $\mathrm{M}^{\mathrm{A}}$ is general for these PBAs during the Cs adsorption process, further confirming the participation of an $\mathrm{M}^{\mathrm{A}}$-modulated mechanism.

\section{Conclusions}

A series of $\mathrm{Fe}_{x} \mathrm{Zn}_{1-x}$-Co PBAs with well-controlled morphology were synthesized by a simple co-precipitation method at room temperature. The as-prepared $\mathrm{Fe}_{x} \mathrm{Zn}_{1-x}$-Co PBAs were used for the sorption of Cs and showed an improved performance as the $\mathrm{Zn}$ : Fe ratio increased. The adsorption capacity of the $\mathrm{Zn}-\mathrm{Co}$ $\mathrm{PBA}$, which appeared to be the most effective adsorbent for Cs, was comparable with the best previously reported values. The results of ICP-OES showed that this highly optimized Cs 
adsorption could be ascribed to the release of larger amounts of $\mathrm{Zn}^{2+}$ into solution compared with $\mathrm{Fe}^{2+}$. A novel $\mathrm{Zn}^{2+}$-modulated $\mathrm{Cs}^{+}$sorption model was thus proposed based on the quantitative correlation between the concentration of ions released from the PBAs and the amount of $\mathrm{Cs}^{+}$ions adsorbed. The model was used to illustrate the optimum Cs sorption of Zn-Co PBA. The Zn-Co PBA may be a promising adsorbent for Cs and the proposed model may help to interpret ion-exchange process in PBAs.

\section{Acknowledgements}

This work was supported by the National Natural Science Foundation of China (21476232, 21403220, 2161101071 and 41573128) and the Chinese Academy of Sciences Visiting Professorships for Senior International Scientists (2011T1G15).

\section{Notes and references}

1 M. I. Hoffert, K. Caldeira, G. Benford, D. R. Criswell, C. Green, H. Herzog, A. K. Jain, H. S. Kheshgi, K. S. Lackner, J. S. Lewis, H. D. Lightfoot, W. Manheimer, J. C. Mankins, M. E. Mauel, L. J. Perkins, M. E. Schlesinger, T. Volk and T. M. L. Wigley, Science, 2002, 298, 981-987.

2 G. L. Kulcinski and J. F. Santarius, Nature, 1998, 396, 724725.

3 D. H. Chestnut, Yearbook of Anesthesiology and Pain Management, 2009, vol. 2009, pp. 252-253.

4 A. B. Kersting, D. W. Efurd, D. L. Finnegan, D. J. Rokop, D. K. Smith and J. L. Thompson, Nature, 1999, 397, 56-59.

5 M. Chino, H. Nakayama, H. Nagai, H. Terada, G. Katata and

H. Yamazawa, J. Nucl. Sci. Technol., 2011, 48, 1129-1134.

6 S. Komarneni and R. Roy, Science, 1988, 239, 1286-1288.

7 S. Komarneni, N. Kozai and W. J. Paulus, Nature, 2001, 410, 771.

8 K. Buesseler, M. Aoyama and M. Fukasawa, Environ. Sci. Technol., 2011, 45, 9931-9935.

9 K. Y. Lee, K. W. Kim, M. Park, J. Kim, M. Oh, E. H. Lee, D. Y. Chung and J. K. Moon, Water Res., 2016, 95, 134-141.

10 S. Komarneni and R. Roy, Nature, 1982, 299, 707-708.

11 M. J. Manos and M. G. Kanatzidis, J. Am. Chem. Soc., 2009, 131, 6599-6607.

12 X. Li, J. Wang, A. I. Rykov, V. K. Sharma, H. Wei, C. Jin, X. Liu, M. Li, S. Yu, C. Sun and D. D. Dionysiou, Catal. Sci. Technol., 2015, 5, 504-514.

13 X. Li, J. Liu, A. I. Rykov, H. Han, C. Jin, X. Liu and J. Wang, Appl. Catal., B, 2015, 179, 196-205.

14 X. Li, A. I. Rykov and J. Wang, Catal. Commun., 2016, 77, 3236.

15 A. Takahashi, H. Tanaka, D. Parajuli, T. Nakamura, K. Minami, Y. Sugiyama, Y. Hakuta, S. Ohkoshi and T. Kawamoto, J. Am. Chem. Soc., 2016, 138, 6376-6379.

16 L. Hu, P. Zhang, Q. W. Chen, J. Y. Mei and N. Yan, RSC Adv., 2011, 1, 1574-1578.

17 A. Ludi, Chimia, 1970, 24, 445-446.

18 F. D. Miles and J. F. Keggin, Nature, 1936, 137, 577-578.
19 A. I. Rykov, J. Wang, T. Zhang and K. Nomura, Hyperfine Interact., 2013, 218, 53-58.

20 T. Vincent, C. Vincent and E. Guibal, Molecules, 2015, 20, 20582-20613.

21 E. R. Nightingale, J. Phys. Chem., 1959, 63, 1381-1387.

22 C. Delchet, A. Tokarev, X. Dumail, G. Toquer, Y. Barré, Y. Guari, C. Guerin, J. Larionova and A. Grandjean, RSC Adv., 2012, 2, 5707.

23 S. C. Jang, Y. Haldorai, G. W. Lee, S. K. Hwang, Y. K. Han, C. Roh and Y. S. Huh, Sci. Rep., 2015, 5, 17510.

24 Y. Lin, G. E. Fryxell, H. Wu and M. Engelhard, Environ. Sci. Technol., 2001, 35, 3962-3966.

25 R. Turgis, G. Arrachart, C. Delchet, C. Rey, Y. Barré, S. PelletRostaing, Y. Guari, J. Larionova and A. Grandjean, Chem. Mater., 2013, 25, 4447-4453.

26 T. Vincent, C. Vincent, Y. Barré, Y. Guari, G. Le Saout and E. Guibal, J. Mater. Chem. A, 2014, 2, 10007-10021.

27 H. Yang, L. Sun, J. Zhai, H. Li, Y. Zhao and H. Yu, J. Mater. Chem. A, 2014, 2, 326-332.

28 K. Benyamin and F. M. Mekhail, Radiochim. Acta, 1991, 55, 95-100.

29 G. S. Ibrahim, F. M. Mekhail and H. F. Aly, Radiochim. Acta, 1987, 42, 53-56.

30 H. Pang, W. Wang, Z. Yan, H. Zhang, X. Li, J. Chen, J. Zhang and B. Zhang, RSC Adv., 2012, 2, 9614.

31 L. Hu, J. Y. Mei, Q. W. Chen, P. Zhang and N. Yan, Nanoscale, 2011, 3, 4270-4274.

32 M. M. Dharman, J.-Y. Ahn, M.-K. Lee, H.-L. Shim, K.-H. Kim, I. Kim and D.-W. Park, Green Chem., 2008, 10, 678.

33 A. Peeters, P. Valvekens, R. Ameloot, G. Sankar, C. E. A. Kirschhock and D. E. De Vos, ACS Catal., 2013, 3, 597-607.

34 X.-K. Sun, X.-H. Zhang, F. Liu, S. Chen, B.-Y. Du, Q. Wang, Z.-Q. Fan and G.-R. Qi, J. Polym. Sci., Part A: Polym. Chem., 2008, 46, 3128-3139.

35 G. Autie-Castro, M. Autie, E. Reguera, J. SantamariaGonzalez, R. Moreno-Tost, E. Rodriguez-Castellon and A. Jimenez-Lopez, Surf. Interface Anal., 2009, 41, 730-734.

36 X.-H. Zhang, Z.-J. Hua, S. Chen, F. Liu, X.-K. Sun and G.-R. Qi, Appl. Catal., A, 2007, 325, 91-98.

37 M. Cao, X. Wu, X. He and C. Hu, Chem. Commun., 2005, 2241-2243, DOI: 10.1039/b500153f.

38 R. McHale, N. Ghasdian, Y. Liu, M. B. Ward, N. S. Hondow, H. Wang, Y. Miao, R. Brydson and X. Wang, Chem. Commun., 2010, 46, 4574-4576.

39 M. Hu, S. Furukawa, R. Ohtani, H. Sukegawa, Y. Nemoto, J. Reboul, S. Kitagawa and Y. Yamauchi, Angew. Chem., Int. Ed. Engl., 2012, 51, 984-988.

40 N. L. Torad, M. Hu, M. Imura, M. Naito and Y. Yamauchi, J. Mater. Chem., 2012, 22, 18261.

41 X. Li, L. Yuan, J. Wang, L. Jiang, A. I. Rykov, D. L. Nagy, C. Bogdan, M. A. Ahmed, K. Zhu, G. Sun and W. Yang, Nanoscale, 2016, 8, 2333-2342.

42 B. Ravel and M. Newville, J. Synchrotron Radiat., 2005, 12, 537-541.

43 A. Ludi and H. U. Güdel, Inorg. Chem., 1973, 1-21. 
44 R. Shannon, Acta Crystallogr., Sect. A: Found. Crystallogr., 1976, 32, 751-767.

45 S. Brunauer, L. S. Deming, W. E. Deming and E. Teller, J. Am. Chem. Soc., 1940, 62, 1723-1732.

46 Y. S. Ho and G. McKay, Process Biochem., 1999, 34, 451-465.

47 H. Freundlich, Zeitschrift Fur Physikalische Chemie-. Stochiometrie Verwandtschaftslehre, 1906, 57, 385-470.

48 I. Langmuir, J. Am. Chem. Soc., 1918, 40, 1361-1403.

49 D. Parajuli, A. Takahashi, H. Noguchi, A. Kitajima, H. Tanaka, M. Takasaki, K. Yoshino and T. Kawamoto, Chem. Eng. J., 2016, 283, 1322-1328.

50 S. Seino, R. Kawahara, Y. Ogasawara, N. Mizuno and S. Uchida, Angew. Chem., Int. Ed. Engl., 2016, 55, 3987-3991. 51 A. Sommer-Marquez, C. Mansas, N. Talha, C. Rey and J. Causse, RSC Adv., 2016, 6, 73475-73484.
52 D. Vu Ca and J. A. Cox, Microchim. Acta, 2004, 147, 31-37. 53 M. Ishizaki, S. Akiba, A. Ohtani, Y. Hoshi, K. Ono, M. Matsuba, T. Togashi, K. Kananizuka, M. Sakamoto, A. Takahashi, T. Kawamoto, H. Tanaka, M. Watanabe, M. Arisaka, T. Nankawa and M. Kurihara, Dalton Trans., 2013, 42, 16049-16055.

54 M. A. Olatunji, M. U. Khandaker, H. N. M. E. Mahmud and Y. M. Amin, RSC Adv., 2015, 5, 71658-71683.

55 K. Clark-Baldwin, D. L. Tierney, N. Govindaswamy, E. S. Gruff, C. Kim, J. Berg, S. A. Koch and J. E. PennerHahn, J. Am. Chem. Soc., 1998, 120, 8401-8409.

56 K. W. Chapman, P. J. Chupas and C. J. Kepert, J. Am. Chem. Soc., 2006, 128, 7009-7014. 